\title{
Characteristics of airborne transmission under stratum ventilation
}

\author{
Tao Huang, Zhengtao Ai ${ }^{*}$, and Arsen Melikov \\ International Center for Indoor Environment and Energy, Department of Civil Engineering, Technical University of Denmark, Lyngby, \\ Denmark
}

\begin{abstract}
The objective of this study is to investigate the characteristics of airborne spread of exhaled droplet nuclei between two occupants in a space conditioned by a horizontal air distribution method, known as stratum ventilation. Experiments were conducted in a full-scale climate chamber. Two breathing thermal manikins were used to simulate a standing infected person and a standing exposed person, respectively. Tracer gas $\left(\mathrm{N}_{2} \mathrm{O}\right)$ was added into the air exhaled by the infected manikin. The tracer gas concentrations in the air inhaled by the exposed manikin and at the ventilation exhaust were continuously monitored. ACH was kept at $2 \mathrm{~h}^{-1}$. The variables in the experiments include the positioning of the manikins, the distance between manikins, and the room air temperature. The horizontal supply airflow to the breathing zone strongly intensifies the mixing between the flow of exhalation and the room air, which reduces the exposure risk of occupants at close proximity and flattens the risk-distance curves. The homogenization of concentration weakens considerably the importance of the relative positioning and location of the infected and exposed persons. All those characteristics of airborne transmission may not be maintained, however, if the horizontal supply jet does not interact directly with the occupants. The findings from this study are intended to contribute for better understanding of airborne transmission indoors.
\end{abstract}

\section{Introduction}

The indoor air quality has concentrated more and more attention for past decades since it is closely concerned with the human health. A high quality indoor environment is of significance to reduce the risk of being infected by airborne pathogen agents, which may cause airborne diseases. Ventilation is widely recognized as one of the most influential engineering methods for controlling airborne transmission indoors [1-4]. There is a strong and sufficient evidence of the relationship between the spread of airborne agents and ventilation [5]. The characteristics of the room airflow are determined by many factors, including the supply air distribution method, the air change rate $(\mathrm{ACH})$, the strength and location of heat source, etc. Many previous studies have focused on investigating the airborne transmission between occupants in rooms conditioned by commonly used total volume air distribution methods, including displacement ventilation (DV), mixing ventilation (MV) and under floor air distribution (UFAD). Kierat et al. [6] investigated the exposure of a doctor and a patient to airborne droplet coughed by a second infected patient in a mock-up hospital premises with MV. Mui et al. [7] numerically modelled the dispersion of exhaled droplet nuclei between an infected manikin and an exposed manikin under MV and DV in an empty room. He et al. [8] studied the transmission behaviours of exhaled aerosols between two occupants under MV, DV and UFAD. Cermak et al. [9] examined the transport of infectious agents associated with exhaled air and bioeffuents between two occupants under the application of personalized ventilation (PV) in conjunction with MV and DV respectively. However, there has been little discussion regarding stratum ventilation (SV) in this field.

SV uses air inlets and outlets mounted on the walls, such that the clean air is supplied directly into the breathing zone. It has been found that SV not only could achieve good indoor thermal comfort [10] and consumes less energy [11] but also had the high ventilation effectiveness [12]. Lin et. al [13] found that the air age was younger, and the $\mathrm{CO}_{2}$ concentration was lower under SV condition compared the other air distributions. However, it is still a query whether its performance on reducing the risk of airborne infection is better in comparison to the conventional ventilation strategies (MV and DV). In this study, the characteristics of airborne speared of exhaled droplet nuclei between two occupants under SV were investigated experimentally. The findings from this study are intended to contribute for better understanding of airborne transmission indoors.

\footnotetext{
*Corresponding author: zheai@byg.dtu.dk
} 


\section{Method}

\subsection{Experimental setup}

The experiment was performed in a climate chamber $\left(\mathrm{L} * \mathrm{~W} * \mathrm{H}=4.4 * 4.7 * 2.6 \mathrm{~m}^{3}\right)$ located at International Center for Indoor Environment and Energy, Technical University of Denmark. The chamber was situated in a tall hall, where the temperature was controlled to be equal to the air temperature in the chamber. The envelope of the chamber was well-insulated to reduce heat transfer. Six ceiling-mounted light fixtures (18 W each) provided the background light. The clean air was supplied with air change rate $(\mathrm{ACH})$ of $2 \mathrm{~h}^{-1}$ through four circular textile openings in diameter of $0.16 \mathrm{~m}$ installed on the side wall at the height of $1.9 \mathrm{~m}$, and exhausted through openings with same configuration in the opposite side (Fig. 1). The supply air was equally balanced among the four openings. Two breathing thermal manikins, shaped as $1.7 \mathrm{~m}$ tall Scandinavian women, were employed to resemble the occupants. They were dressed in summer attire, giving a total clothing insulation of $0.5 \mathrm{clo}$, and each manikin dissipated $80 \mathrm{~W}$ sensible heat load. One of the manikins (infected manikin) was used to simulate the infected occupant. It was placed $1.1 \mathrm{~m}$ away from the air supplies (see P in Fig. 1). The second manikin (exposed manikin) was used to mimic the exposed occupant. They were equipped with an artificial lung to simulate the respiratory process [14]. The breathing cycle was $2.5 \mathrm{~s}$ inhalation, $2.5 \mathrm{~s}$ exhalation and $1.0 \mathrm{~s}$ pause. The pulmonary ventilation rate was set as $6 \mathrm{~L} / \mathrm{min}$ [15]. The breathing mode for the "infected" manikin was nose inhalation and mouth exhalation, while the exposed manikin acted in the conversed way.

$\mathrm{N}_{2} \mathrm{O}$ tracer gas was used to simulate airborne droplets and droplet nuclei during all experiments. It has been tested that gas was reliable to predict the exposure to fine sized particles [16]. $\mathrm{N}_{2} \mathrm{O}$ was dosed into the air exhaled by the infected manikin with a dosing rate of 0.2 $\mathrm{L} / \mathrm{min}$. The $\mathrm{N}_{2} \mathrm{O}$ fraction of the exhaled air from the infected manikin was ca. 1.3\%. During the experiments, the pressure inside of the chamber was kept slightly lower than the pressure of the tall hall to avoid tracer gas leakage.



Fig. 1. Schematic view of the full-scale climate chamber (a), the different types of positioning of the two breathing thermal manikins (a)-(e); the separation distance 'D' between occupants refers to the mouth-to-mouth distance.

\subsection{Measured parameters and instrumentation}

The concentration of the tracer gas was measured with a set of fast gas concentration meters, developed by Kierat et al. [17]. The sampling rate was $4 \mathrm{~Hz}$, which can achieve nearly uninterrupted measurement, thereby making it easier to distinguish the inhalation and exhalation processes. The expanded uncertainty was $\pm 20.0 \mathrm{ppm}$ (95\% confidence level). There were 4 measuring points: 1) in the infected manikin's mouth (exhaled air), 2) in the exposed manikin's mouth (inhaled air), 3) in the exposed manikin's nose (exhaled air), 4) in the air exhaust. All the measuring points were arranged according to the recommendations suggested by Melikov [18]. The dosing and the measurement of concentration started when the flow field in the chamber reached stabilization. Each measurement lasted at least 1 $\mathrm{h}$ to obtain enough data.

\subsection{Experimental conditions}

Seven cases, including 42 conditions with regard to five positionings, nine separation distances between occupants referring to mouth-to-mouth distance and three room air temperatures, were performed in the experiments. The positionings of the manikins included: face to face, face to back and side by side, see Fig. 1. In each positioning, the exposed manikin was placed at the same vertical plane with the infected manikin. The separation distance was changed from condition to condition as defined in Table 1. Most of the experiments were performed at $24{ }^{\circ} \mathrm{C}$. Selected experiments were performed at $22{ }^{\circ} \mathrm{C}$ and $28{ }^{\circ} \mathrm{C}$ as well (defined in Table 1). The maximum separation distance was $2.0 \mathrm{~m}$. Details for each case are enclosed in Table 1.

\subsection{Data analyses}

The measured tracer gas concentration in the inhaled air of the exposed manikin and in the exhaust air was normalized to susceptible exposure index $\left(\varepsilon_{i}\right)$ [19] as described in Equation (1):

$$
\varepsilon_{i}=\left(C_{\text {in }}-C_{s}\right) /\left(C_{\text {exhaust }}-C_{s}\right)(1)
$$

where, $C_{i n}$ was the concentration in the air inhaled by exposed manikin (ppm), $C_{s}$ was the concentration at air supply (ppm) $C_{\text {exhaust }}$ was the concentration at air exhaust (ppm). In this experiment, there was no tracer gas concentration in the supply air, thus $\varepsilon_{i}=C_{i n} / C_{\text {exhaust. }}$ A high susceptible exposure index indicated that relative high amount of $\mathrm{N}_{2} \mathrm{O}$ was inhaled by the exposed occupant, thereby meaning the risk of infection was high. Unity of $\varepsilon_{i}$ reflected that the air in the room was fully mixed.

\section{Results and analyses}

\subsection{Influence of separation distance}


Fig. 2 showed the distribution of the susceptible exposure index $\left(\varepsilon_{i}\right)$ in relation to the separation distance

between two manikins. The data included in this part

Table $1 \mathrm{~A}$ List of experimental conditions; full set of separation distance includes $0.35,0.45,0.6,0.8,1.0,1.2,1.4,1.6,1.8$ and $2.0 \mathrm{~m}$ $\left(\mathrm{ACH}=2 \mathrm{~h}^{-1} ; \mathrm{P}=1.1 \mathrm{~m}\right)$.

\begin{tabular}{lllll}
\hline Cases & Conditions & $\begin{array}{l}\text { Positioning of two } \\
\text { manikins }\end{array}$ & $\begin{array}{l}\text { Room air } \\
\text { temperature }\left({ }^{\circ} \mathbf{C}\right)\end{array}$ & Separation distance (m) \\
\hline 1 & $1-10$ & $\mathrm{~A}$ & 24 & $0.35,0.45,0.6,0.8,1.0,1.2,1.4,1.6,1.8,2.0$ \\
2 & $11-13$ & $\mathrm{~B}$ & 24 & $0.35,0.5,1.0$ \\
3 & $14-16$ & $\mathrm{C}$ & 24 & $0.35,0.5,1.0$ \\
4 & $17-19$ & $\mathrm{D}$ & 24 & $0.35,0.5,1.0$ \\
5 & $20-22$ & $\mathrm{E}$ & 24 & $0.35,0.5,1.0$ \\
6 & $23-32$ & $\mathrm{~A}$ & 28 & $0.35,0.45,0.6,0.8,1.0,1.2,1.4,1.6,1.8,2.0$ \\
7 & $33-42$ & $\mathrm{~A}$ & 22 & $0.35,0.45,0.6,0.8,1.0,1.2,1.4,1.6,1.8,2.0$ \\
\hline
\end{tabular}

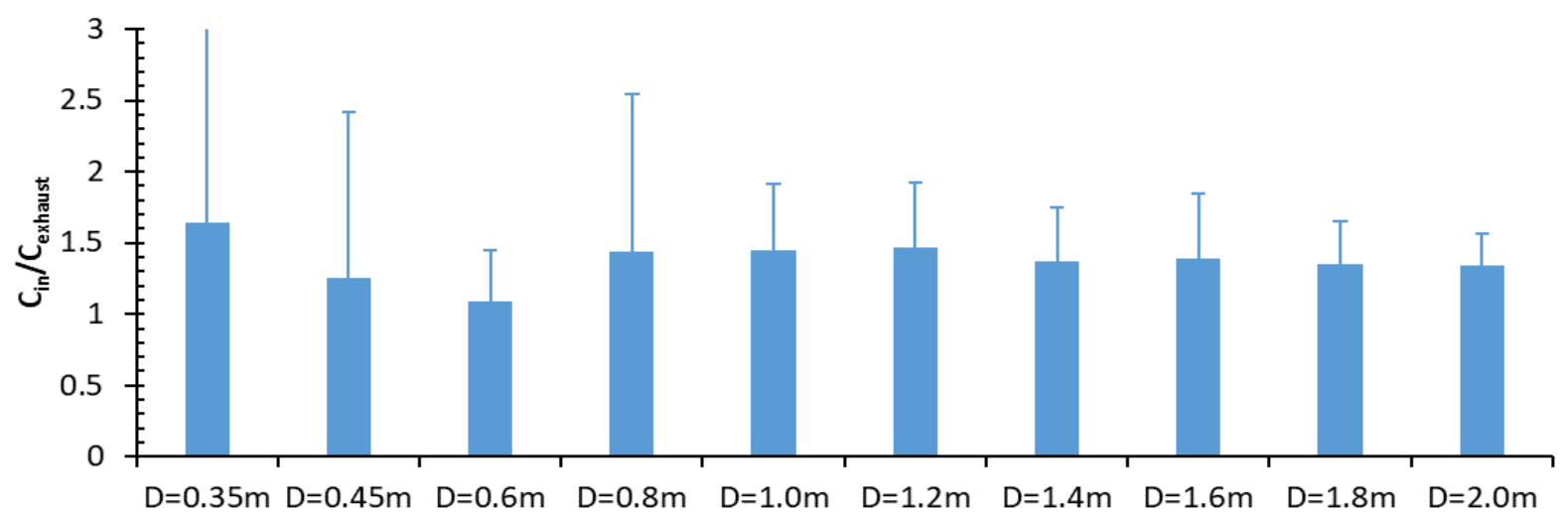

Fig. 2. Influence of separation distance on the mean exposure index when ACH equals to $2.0 \mathrm{~h}^{-1}$.

were selected from condition 1-10 with the room air temperature of $24{ }^{\circ} \mathrm{C}$ and positioning A. It could be observed that the exposure index reached the highest value of ca. 1.6 when the separation distance was $0.35 \mathrm{~m}$ and decreased to the lowest value of ca. 1.1 when the separation distance was increased to $0.6 \mathrm{~m}$. Further increasing the separation distance, the exposure index almost stabilised at 1.3. In general, there was no conspicuous difference among all the conditions. This phenomenon was different with the previous studies. For instance, Nielson et al. [20] and Liu et al. [21] both found that under DV the exposure index was the highest at close proximity and decayed rapidly as the separation distance increases. At the remote distance the exposure index could drop below unity. Moreover, the results from Nielson's showed that at proximity the susceptible exposure index could reach to seven times higher than that in the remote distance. In those two studies, the susceptible exposure index experienced a steep decay before it came to unity at the remote distance from the pollutant sources. However, these phenomena were all absent in Fig. 2. The maximum index was only 1.5 times higher than the minimum value, and in all studied conditions the exposure index was always above unity. These relatively uniform exposure indices indicated that the air in the room was in a well-mixed state, thus the concentration of tracer gas was distributed homogeneously, leading to a condition that the exposure index was nearly changeless no matter the separation distance between the manikins. However, at close proximity the risk of being infected was still higher than the other places. This was because that the separation distance was too close to enable the exposed manikin inhaled the air which had been fully diluted by the surrounding clean air. The decreasing trend from $0.35 \mathrm{~m}$ to $0.6 \mathrm{~m}$ reflected that a continuous dilution occurred in this zone, indicating the active length of the air jet under $\mathrm{SV}$ with $2 \mathrm{~h}^{-1} \mathrm{ACH}$ was ca. $0.6 \mathrm{~m}$. Since the clean air jet could not penetrate the area which, was beyond the separation distance of $0.6 \mathrm{~m}$, the tracer gas concentration became consistent at the remote distances. The results also manifested that SV could enhance the air mixing between the polluted air and the room air under such a condition, which reducing the exposure risk of occupants in the close proximity and flattening the risk-distance curve.

\subsection{Influence of occupants' positioning}

The influence of occupants' positioning on the mean exposure index regarding different separation distances was shown in Fig. 3. It needed to be mentioned that obstructed by the structural support of the thermal manikins, the minimum separation distance was limited to $0.6 \mathrm{~m}$ for Layout $\mathrm{C}$ and $\mathrm{D}$, and $1.0 \mathrm{~m}$ for Layout $\mathrm{E}$. At close proximity, the exposure index of Layout B was double higher than Layout A. Interestingly, for Layout B the infected manikin was placed at the downstream direction. The reason contributed to this phenomenon was that in terms of Layout B the supply airflow jet impinged the first manikin and created a low-pressure region behind it, which sucked the air from surroundings, leading to the higher tracer gas concentration. With the increase of the separation distance to $0.5 \mathrm{~m}$ and $1.0 \mathrm{~m}$, the exposure index in each 
condition tended to be uniform to ca. 1.0. This was consistent with the discussion in the section 3.1, that the air in the remote area was fully mixed, thus the tracer gas concentration was nearly homogeneous. However, it still could be found that the face-to-face layout always related to the highest exposure index among other conditions. This was because the exposed occupant was standing on the way toward the infected manikin, resulting in a straightforward transmission route. In contrast, in Layout $\mathrm{C}$ there was no direct transmission and the well mixing has achieved at $1.0 \mathrm{~m}$ away from the infected manikin. In the previous studies, Bolashikov et al. [22] investigated the exposure of health care workers and occupants to the airborne pathogens in a hospital patient room with MV and she found that the exposure of the doctor standing near the bed of the patient and turned side was nearly 50 times lower than when the doctor was facing the patient. However, the results from the present study in general revealed that the layout of the infected and exposed manikins posed less influence on the exposure risk, even at close proximity, the maximum exposure index only reached to ca. 2.9. This manifested again that the pollutant concentration was relatively uniformly distributed under SV, thereby weakening considerably the importance of the relative positioning and location of the occupants.



Fig. 3. Influence of occupants positioning on the mean exposure index when $\mathrm{ACH}$ equals to $2.0 \mathrm{~h}^{-1}$.

\subsection{Influence of room air temperature}

Fig. 4 showed the influence of three room air temperatures, $22{ }^{\circ} \mathrm{C}, 24{ }^{\circ} \mathrm{C}, 28{ }^{\circ} \mathrm{C}$ on the exposure index regarding different separation distances. The room air temperature was indicated by the exhaust air temperature. A similar general trend could be found as shown in Fig. 2. The exposure index reached the highest value then decayed to nearly unity with the increase of the separation distance. With regard to room air temperature, the highest exposure index could always be observed when room air temperature was $28{ }^{\circ} \mathrm{C}$ and never below 2.0 at close distance from $0.35-0.8 \mathrm{~m}$. When room air temperature was $24{ }^{\circ} \mathrm{C}$ and $22{ }^{\circ} \mathrm{C}$, there is no conspicuous difference between the measured values. At the remote distance, the exposure index tended to be unity at each condition. The highest exposure index of 6.4 could be observed when the separation distance was $0.35 \mathrm{~m}$ with room air temperature of $28{ }^{\circ} \mathrm{C}$. This indicated that the infectious risk was six times higher compared with remote area in the chamber. Moreover, with room air temperatures of $22{ }^{\circ} \mathrm{C}$ and $24{ }^{\circ} \mathrm{C}$ the exposure index was always lower than 2 and decreased to ca. 1 when separation distance was increased to 0.45 $\mathrm{m}$. However, at the room air temperature of $28{ }^{\circ} \mathrm{C}$, the exposure index declined to unity until the separation distance was higher than $1.0 \mathrm{~m}$, which was longer than the other two room temperatures. This reflected that high room temperature would weaken the mixing capability of SV, thereby prolonging the dilution time. The reason was that since the supply air temperature was nearly same with the room air temperature, due to the thermal plume above the manikins, the clean air jet flowed upwards and interacted little with the thermal manikin, which therefore resulted in an inadequate mixing and a high exposure in the breathing zone. In this situation, the influence of the separation distance became important.

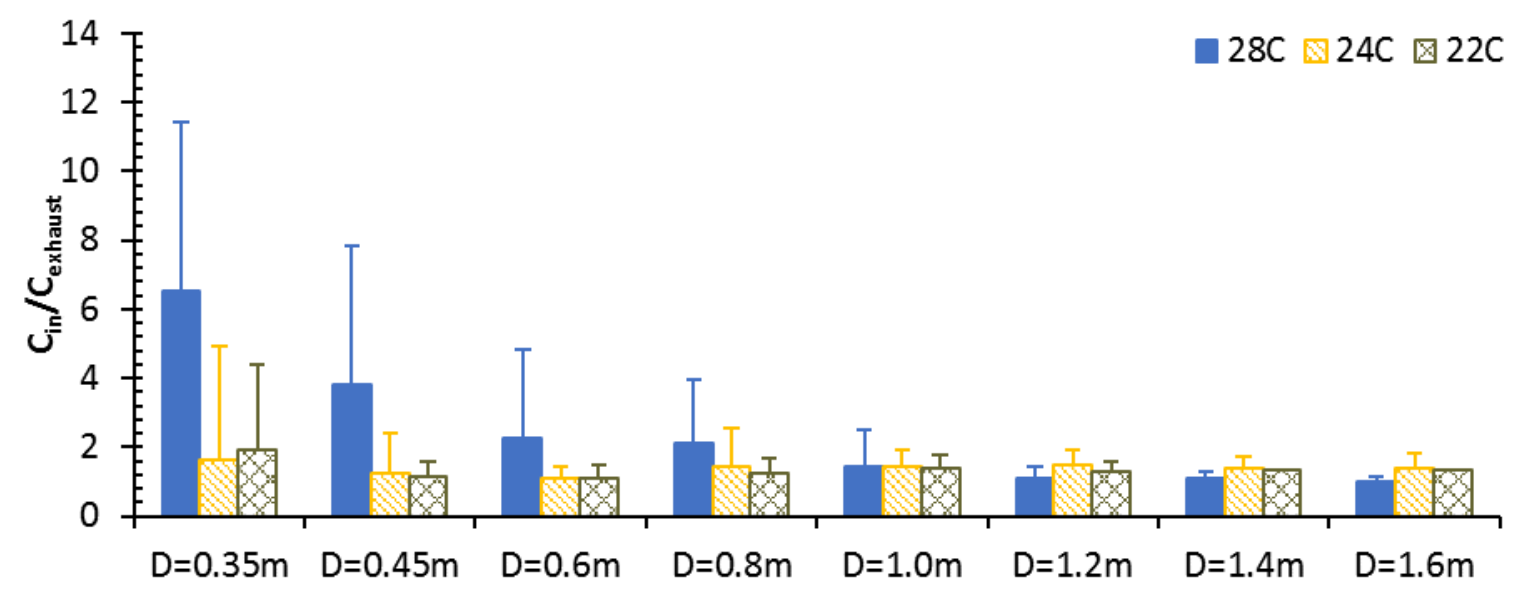

Fig. 4. Influence of room air temperature $\left(\mathrm{ACH}=2 \mathrm{~h}^{-1}\right.$; Positioning $\left.\mathrm{A}\right)$, where the room air temperature is indicated by the exhaust air temperature. 


\section{Conclusions}

The airborne transmission between two occupants under SV was investigated using full-scale laboratory test. The full size breathing thermal manikins were used to simulate infected and exposed occupants. The impact of the separation distance and positioning of the manikins and the room air temperature on the exposure index was studied. The main conclusions are as follows:

1. Stratum ventilation strategy (SV) strongly intensified the mixing between the flow of exhalation and the room air, which reduced the exposure risk of occupants at close proximity and flattened the risk-distance curve;

2. Due to the homogeneous pollution concentration in the room, the relative positioning and location of the infected and exposed occupants were of less importance regarding the exposure risk;

3. If the supply airflow did not interact directly with the breathing zone, higher exposure index at close proximity appeared again and the influence of the separation distance became important.

\section{Acknowledgement}

This research was supported partially by grant from the People Programme (Marie Curie Actions) of the European Union's Seventh Framework Programme (FP7/2007-2013) under REA grant agreement no. 609405 (COFUNDPostdocDTU) and partially by the European Union $7^{\text {th }}$ framework program HEXACOMM FP7/2007e2013 under grant agreement No 315760.

\section{Reference}

1. Streifel A. Hospital Epidemiology and Infection Control, 2e., Chapter 80, Lippincott Williams \& Wilkins, Philadelphia, USA (1999).

2. Kaushal V, Saini P.S, Gupta A.K. Environmental Control Including Ventilation in Hospitals. JK Science. 6, 229-232 (2004).

3. Beggs C.B,Kerr K.G, Noakes C.J, Hathway E.A, Sleigh P.A. The ventilation of multiple-bed hospital wards: Review and analysis, American Journal of Infection Control. 36, 250-259. (2008) DOI: 10.1016/j.ajic.2007.07.012

4. Ai Z.T, Melikov A.K. Airborne spread of expiratory droplet nuclei between the occupants of indoor environments: A review. Indoor Air. 28, 500-524. (2018) DOI: 10.1111/INA.12465.

5. Li Y, Leung G.M, Tang J.W, Yang X, Chao C.Y.H, Lin J.Z, Lu J.W, Nielsen P.V, Niu J, Qian H, Sleigh A.C, Su H.J, Sundell J, Wong T.W, Yuen P.L. Role of ventilation in airborne transmission of infectious agents in the built environment-a multidisciplinary systematic review. Indoor Air. 17, 2-18 (2007). DOI: $10.1111 /$ j.1600-0668.2006.00445.x

6. Kierat W., Bolashikov Z.D., Melikov A.K., Popiołek, Z., Exposure to coughed airborne pathogens in a double bed hospital patient room with overhead mixing ventilation: impact of posture of coughing patient and location of doctor, IAQ 2010: Airborne Infection Control - Ventilation, IAQ \& Energy, Paper ID: TOPC-00128-2010, November 10th-12th, Kuala Lumpur, Malaysia (2010).

7. Mui K.W, Wong L.T, Wu C.L, Lai A.C.K. Numerical modeling of exhaled droplet nuclei dispersion and mixing in indoor environments. Journal of Hazardous Materials. 167, 736-44 (2009). DOI: https://doi.org/10.1016/j.jhazmat.2009.01.041

8. He Q.B, Niu J.L, Gao N.P, Zhu T, Wu J.Z. CFD study of exhaled droplet transmission between occupants under different ventilation strategies in a typical office room. Building and Environment. 46, 397-408 (2011). DOI: https://doi.org/10.1016/j.buildenv.2010.08.003

9. Cermak R, Melikov A.K, Forejt L, Kovar O. Performance of Personalized Ventilation in Conjunction with Mixing and Displacement Ventilation, HVAC\&R Research. 12 (2), 295-311 (2006).

DOI: https://doi.org/10.1080/10789669.2006.10391180

10. Fong M.L, Lin Z, Fong K.F, Chow T.T, Yao T. Evaluation of thermal comfort conditions in a classroom with three ventilation methods. Indoor Air. 21(3), 231-9 (2011). DOI: 10.1111/j.16000668.2010.00693.x

11. Lin Z, Lee C.K, Fong S, Chow T.T, Yao T, Chan A.L.S. Comparison of annual energy performances with different ventilation methods for cooling. Energy and Building. 43, 130-6 (2011). DOI : https://doi.org/10.1016/j.enbuild.2010.08.033

12. Tian L, Lin Z, Wang Q. Experimental investigation of thermal and ventilation performances of stratum ventilation. Building and Environment. 46, 1309-20 (2011).

DOI: https://doi.org/10.1016/j.buildenv.2011.01.002

13. Lin Z, Wang J, Yao T, Chow T.T. Investigation into anti-airborne infection performance of stratum ventilation. Building and Environment. 54, 29-38 (2012). DOI: https://doi.org/10.1016/j.buildenv.2012.01.017

14. Melikov A.K, Kaczmarczyk J, Cygan L Indoor air quality assessment by a breathing thermal manikin. Indoor Air. 17, 50-59 (2000).

15. Hyldgaard C.E. Humans as a source of heat and air pollution. In: Proceedings of ROOMVENT '94, 4th International Conference on Air Distribution in Rooms, Krakow, Poland. 414-433 (1994).

16. Bivolarova M, Ondracek J, Melikov A.K, Zdimal V. A comparison between tracer gas and aerosol particles distribution indoors: The impact of ventilation rate, interaction of airflows, and presence 
of objects. Indoor Air. 27, 1201-1212 (2017). DOI: 10.1111/ina. 12388

17. Kierat W, Popiolek Z. Dynamic properties of fast gas concentration meter with nondispersive infrared detector. Measurement. 95, 149-155 (2017). DOI : https://doi.org/10.1016/j.measurement.2016.10.008

18. Melikov A.K. Breathing thermal manikins for indoor environment assessment: important characteristics and requirements. European Journal of Applied Physiology. 92, 710-713 (2004). DOI: 10.1007/s00421-004-1142-1

19. Qian H, Li Y. Removal of exhaled particles by ventilation and deposition in a multibed airborne infection isolation room. Indoor Air. 20, 284-297 (2010). DOI: $10.1111 /$ j.1600-0668.2010.00653.x

20. Nielsen P.V, Winther F.V, Buus M, Thilageswaran M. Contaminant flow in the microenvironment between people under different ventilation conditions. ASHRAE Transactions. 114, 632-638. (2008)

21. Liu L, Li, Y, Nielsen P.V, Wei J, Jensen R.L. Shortrange airborne transmission of expiratory droplets between two people. Indoor Air. 27, 452-462. (2017) DOI: 10.1111/ina.12314

22. Bolashikov Z.D, Melikov A.K, Kierat W, Popiołek $Z$, Brand M. Exposure of health care workers and occupants to coughed airborne pathogens in a double-bed hospital patient room with overhead mixing ventilation, HVAC\&R Research. 18, 602615 (2012). DOI : https://doi.org/10.1080/10789669.2012.682692. 